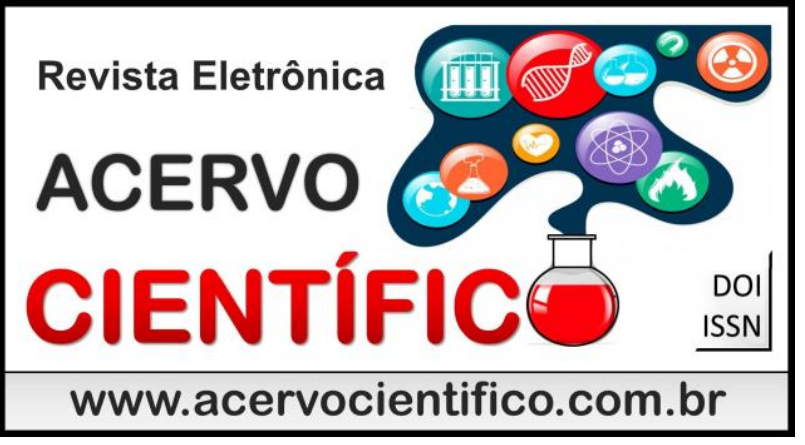

DOI: 10.25248/REAC35_2018

Recebido em: 10/2018

Aceito em: 10/2018

Publicado em: 11/2018

\title{
Responsabilidade Civil do Estado: Conduta Omissiva
}

\author{
Civil Liability Of The State: Omissive Conduct \\ Responsabilidad Civil Del Estado: Conducta Omissiva
}

Fernando Heck ${ }^{1}$

\begin{abstract}
Resumo: Sendo um tema ainda muito debatido, a responsabilidade civil do Estado por omissão, após diversas decisões e posicionamentos do Supremo Tribunal Federal, passou a direcionar sob nova forma. Aquilo que diversos autores, durante muito tempo vinham sustentando, demonstra-se notório nos dias atuais. Visa, portanto, o presente artigo, apresentar uma perspectiva abrangente sobre os entendimentos atualmente adotados pela jurisprudência, bem como seus aspectos doutrinários no que tange à responsabilidade civil do Estado no caso de omissão, além de apresentar os fundamentos constitucionais, incorporados à referida responsabilidade. Destacando também a evolução histórica da responsabilidade civil do Estado, o trabalho acabou resultando na averiguação da existência de uma grande controvérsia, principalmente quanto aos institutos das responsabilidades subjetiva e objetiva, que ainda hoje são polarizadas.
\end{abstract}

Palavras-chave: Responsabilidade Civil do Estado; Conduta Omissiva; Artigo 37, § 6으 da Constituição Federal do Brasil; Jurisprudência dos tribunais superiores.

\begin{abstract}
State's civil responsibility by omission, a topic still much debated, after many decisions of Federal Supreme Court, started to direct to a new form. For a long time, many authors advocated ideas, which are accepted currently. This paper aims to introduce a wide perspective about the State's civil responsibility by omission, including the jurisprudence's positions, as well as its doctrinal aspects, and the constitutional grounds. Also considering the historical evolution of the theme, this article resulted in the investigation of the existence of a great controversy, mainly regarding the institutes of the subjective and objective responsibilities, which still are polarized today.
\end{abstract}

Keywords: Civil Liability of the State; Omissive Conduct; Article 37, § 6 of the Federal Constitution of Brazil; Jurisprudence of higher courts.

Resumen: Siendo un tema aún muy debatido, la responsabilidad civil del Estado por omisión, tras varias decisiones y posicionamientos del Supremo Tribunal Federal, pasó a dirigir bajo nueva forma. Lo que varios autores, durante mucho tiempo venían sosteniendo, se demuestra notorio en los días actuales. Por lo tanto, el presente artículo, presentar una perspectiva exhaustiva sobre los entendimientos actualmente adoptados por la jurisprudencia, así como sus aspectos doctrinales en lo que se refiere a la responsabilidad civil del

${ }^{1}$ Bacharel em Direito pela Universidade de Santa Cruz do Sul (UNISC), Santa Cruz do Sul - RS, Especialização em Direito Civil e Processo Civil (em andamento) pela Universidade Regional Integrada do alto Uruguai e das Missões (URI), campus Santiago - RS. Procurador Jurídico do município de Bossoroca RS. E-mail: fernando heck@hotmail.com 
Estado en caso de omisión, además de presentar los fundamentos constitucionales, incorporados a dicha responsabilidad. Destacando también la evolución histórica de la responsabilidad civil del Estado, el trabajo acabó resultando en la averiguación de la existencia de una gran controversia, principalmente en cuanto a los institutos de las responsabilidades subjetiva y objetiva, que aún hoy se polarizan.

Palabras clave: Responsabilidad Civil del Estado; Conducta omnisciente; Artículo 37, $\S$ 60 de la Constitución Federal de Brasil; Jurisprudencia de los tribunales superiores.

\section{INTRODUÇÃO}

Cumpre mencionar, que o estágio da civilização reflete na teoria da responsabilidade civil do Estado, sendo que com a evolução, se amoldura, cede ou acaba por dar lugar às novas acepções, tendo em vista que o direito é dinâmico, acompanhando o progresso da sociedade.

No sistema jurídico brasileiro, jamais encontrou sustentação a teoria da irresponsabilidade, embora existente Contencioso Administrativo no período do Império, afirma-se que no Brasil, jamais prevaleceu a irresponsabilidade do Estado através dos atos lesivos dos seus representantes.

Segundo Meirelles (1993, p.557) ao passo em que os agentes públicos - no desempenho de suas atribuições - causarem dano a terceiro, nasce a responsabilidade do Estado, cabendo à Fazenda Pública a obrigação de compor o dano causado.

Carvalho Filho (2005, p.425), assevera que havendo situação em que o próprio direito trate da responsabilidade, sobrevém indução de imediato à circunstância de alguém, devendo, portanto, responder e ser responsabilizado no tocante da ordem jurídica existente, uma vez que procedente a averiguação dos fatos.

Portanto, ensina que toda responsabilidade gera sanção, no caso a indenização ou reparação daqueles prejuízos causados pelo agente responsável, nos danos causados a terceiros.

A responsabilidade civil do Estado desponta na relação obrigacional que the incumbe de reparar economicamente os danos lesivos na seara juridicamente garantida de outrem. Devendo, ainda, que mediante comportamentos lícitos ou ilícitos, omissivos ou comissivos, the sejam imputáveis a responsabilidade.

No tocante da responsabilidade extracontratual, sustenta-se que nada mais é, do que uma relação obrigacional para reparação de danos causados a terceiros, decorrente de atuações omissivas ou comissivas, lícitos ou ilícitos, omissivos ou comissivos, passíveis de imputabilidade aos agente públicos (DI PIETRO, P.524).

Percebe-se que as definições supracitadas demonstram preocupação para identificar quais são os sujeitos que formam a relação jurídica, partindo da ocorrência do dano.

O Estado figura o polo passivo porque torna-se juridicamente responsável por seu comportamento, que de alguma forma, o ordenamento considera relevante, enquanto o particular que experimentou o dano ou prejuízo, passará a figurar o polo ativo da relação.

No que tange à responsabilidade do Estado, das análises conceituais, importante destacar os elementos inarredáveis para configurar a responsabilidade, sendo eles: a conduta estatal lesiva que, necessariamente, se reveste da forma comissiva ou omissiva; o dano e o nexo de causalidade entre o comportamento estatal - que torna este ente sujeito obrigado à reparação - e o prejuízo experimentado pelo particular - que o torna sujeito beneficiário da reparação.

Destarte, o comportamento do Estado se exterioriza por intermédio de seus agentes ou prepostos, que agem na condição de representantes públicos, e, quando no seu exercício das atividades inerentes do órgão estatal vierem a praticar atos que gerem danos à terceiros, restará configurada a responsabilidade civil do Estado, gerando a este o dever de indenizar (PEREIRA, 2004). 
Ante ao exposto, pode-se afirmar que a responsabilidade civil do Estado é o dever jurídico imposto para reparação de um dano experimentado por particular, seja por conduta comissiva ou omissiva dos seus agentes.

\section{ANÁLISE QUANTO À APLICABILIDADE DO PRINCÍPIO DA LEGALIDADE NAS CONDUTAS OMISSIVAS}

O princípio da legalidade é pilar da Administração Pública, expresso no art. 37, caput da Constituição Federal, referindo que qualquer dos Poderes (União, Estado, Distrito Federal e Municípios) obedecerão aos princípios da moralidade, publicidade, eficiência, impessoalidade e, notadamente, ao da legalidade.

Significa o princípio da legalidade, que a lei determinará os mandamentos com base nas exigências do bem comum aos agentes, devendo ou não devendo cumprir, constituindo, portanto, uma conduta omissiva ou comissiva.

No tocante da Constituição Federal de 1988, percebe-se a inexistência expressa quanto ao princípio da finalidade, admitindo, entretanto, o reconhecimento frente ao princípio da impessoalidade, que constituem fundamentos da ação administrativa, sustentando a própria atividade pública. Não podem estes serem renegados, sob pena de desvirtuar a gestão dos negócios públicos e tornar esquecido o que é elementar no tocante da boa guarda e zelo dos interesses sociais (MEIRELES, p.87).

Exemplificando norma positiva de conduta omissiva ou comissiva, que caracterize ato de improbidade, vale notar o que preconiza o artigo 11 da Lei 8.429/92, versando sobre o enriquecimento ilícito, se constituindo "ato de improbidade administrativa, que atenta contra os princípios da administração pública, qualquer ação ou omissão que viole os deveres de honestidade, imparcialidade, legalidade e lealdade às instituições".

Nesse ínterim, considerando, ainda, o princípio da legalidade, a Administração não tem escolha, podendo fazer somente o que a lei autoriza, não cabendo descumprimento. Na conduta omissiva, ao agente público é existente o dever legal de agir, e quando a obrigação não é cumprida pelo administrador no exercício de seus deveres, gerando prejuízo a terceiro, configura o dever de indenizar.

Bandeira de Mello (2007, p.89) afirma que o princípio da legalidade é basilar no ordenamento jurídico Administrativo, impondo que nasce para o Estado de Direito, uma submissão do Estado à lei, ficando este estreitamente vinculado com relação ao seu modo de atuar.

Para a conduta dos agentes da administração, tem-se como diretriz básica o princípio da legalidade, devendo a lei autorizar as atividades, sob pena de vir a ser considerada como uma conduta ilegal.

Cabe lembrar que, no caso de haver dissonância entre a lei e a conduta, deverá esta ser corrigida no intuito de eliminar-se a ilicitude, haja vista que é ilegítima a atividade do administrador público se não estiver em conformidade com o disposto na lei.

\section{OMISSÃO DO ESTADO - RESPONSABILIDADE OBJETIVA E SUBJETIVA}

Em primeiro plano, importante balizar a controvérsia acerca da teoria da responsabilidade objetiva nas hipóteses de condutas omissivas, encontrando-se no artigo 37, § 6으 da Constituição Federal (CF), quando a expressão "causarem a terceiros" traz divergência entre os doutrinadores, havendo aqueles que endentem pela natureza do verbo "causar", direcionamento para uma ação positiva, não ingressando no referido dispositivo, as omissões.

Tratando do referido dispositivo constitucional que versa sobre a responsabilidade civil do Estado, Meirelles (2006, p. 654):

Nessa substituição da responsabilidade individual do servidor pela responsabilidade genérica do Poder Público, cobrindo o risco de sua ação omissão, é que assenta a teoria da responsabilidade objetiva da Administração, vale dizer, da responsabilidade sem culpa, pela só ocorrência da falta anônima do serviço, porque esta falta está, precisamente na área dos riscos assumidos pela Administração para a consecução de seus fins. 
Revista Eletrônica Acervo Científico / Electronic Journal Science Collection ISSN 2595-7899

Para o autor, adota-se a teoria da responsabilidade objetiva, quer seja nas ações, ou nas omissões adotadas pelo Poder Público.

Adota-se, todavia, a teoria da responsabilidade subjetiva do Estado pela sua omissão que gere dano, afirmando, só haver responsabilização no caso de coexistir a obrigatoriedade de evitar ou impedir o dano, mediante descumprimento de preceito legal.

No caso de não existir obrigação de reparar ou impedir eventual dano, por conseguinte, faltaria subsistente razão para que ao Poder Público fossem impostas responsabilidades de suportar patrimonialmente o que vier a ser consequência da lesão.

Partindo deste ponto, toda responsabilidade imposta ao Estado por ato omissivo, somente será oriunda de um ato ilícito. Assim, a responsabilidade sendo imputada pela realização de um ato ilícito, será necessariamente subjetiva, uma vez que não havendo conduta ilícita do Estado - embora possa ocorrer por parte do particular - ou seja, sem verificação de um atuar mediante imperícia (culpa), negligência ou imprudência, ou, ainda, com o deliberado propósito para que a norma constituída em determinada obrigação (dolo) seja violada, não subsistirão elementos necessários para responsabilização, uma vez que culpa e dolo são as formas elementares de responsabilidade subjetiva (MELLO, 2007, p. 487).

Salienta-se, que a hipótese de responsabilidade subjetiva fica restrita àqueles casos de omissão e não aos danos que dependam de situação produzida pelo Estado diretamente propiciatória, onde a responsabilidade é objetiva, como no caso de assassinato de um preso por outro.

Para Cavalieri Filho (2007, p. 231) o dispositivo constitucional que gera a controvérsia faz relação tanto para as atividades omissivas quanto comissivas do Estado, em razão de que o ato ilícito seria traduzido verificando simples contrariedade entre a conduta e o dever jurídico imposto pela norma, entretanto, não havendo relação entre elemento subjetivo ou psicológico, servindo, portanto, de fundamento para a responsabilidade objetiva.

Ainda para o autor, (2007, p. 312), quando o Estado cria ou propicia situação para que ocorra o dano, deverá ser responsabilizando, na medida em que existia o dever de impedi-lo. Cita, ainda, como exemplo:

Se o motorista embriagado atropela e mata pedestre que está na beira da estrada, a Administração (entidade de trânsito) não poderá ser responsabilizada pelo fato de estar esse motorista ao volante sem condições. Isso seria responsabilizar a Administração por omissão genérica. Mas se esse motorista, momentos antes, passou por uma patrulha rodoviária, teve o veículo parado, mas os policiais, por alguma razão, deixaram-no prosseguir viagem, aí já haverá omissão específica que se erige em causa adequada do não-impedimento do resultado. Nesse segundo caso haverá responsabilidade objetiva do Estado.

Pode-se perceber que os citados autores desdobram entendimento de que somente nessa circunstância - de situação produzida pelo ente estatal diretamente propiciatória ou omissão específica - é que a responsabilidade será objetiva.

\section{A RESPONSABILIDADE CIVIL DO ESTADO MEDIANTE CONDUTA OMISSIVA, SEGUNDA A PERSPECTIVA DOS TRIBUNAIS BRASILEIROS}

Impende destacar que existe controvérsia sobre o tema, sendo tendência que os Tribunais de Justiça reconheçam, para os casos de omissão, a responsabilidade subjetiva. Nesse sentido firmou entendimento o Supremo Tribunal Federal (STF):

CONSTITUCIONAL. ADMINISTRATIVO. CIVIL. RESPONSABILIDADE CIVIL DAS PESSOAS PÚBLICAS. ATO OMISSIVO DO PODER PÚBLICO: LATROCÍNIO PRATICADO POR APENADO FUGITIVO. RESPONSABILIDADE SUBJETIVA: CULPA PUBLICIZADA: FALTA DO SERVIÇO. C.F., art. 37, § 6ㅇ.- Tratando-se de ato omissivo do poder público, a responsabilidade civil por tal ato é subjetiva, pelo que exige dolo ou culpa, esta numa de suas três vertentes, a negligência, a imperícia ou a imprudência, não sendo, entretanto, necessário individualizá-la, dado que pode ser atribuída ao serviço público, de forma genérica, a falta do serviço. Il. - A falta do serviço - faute du service dos franceses - não dispensa o requisito da causalidade, vale dizer, do nexo de 
causalidade entre a ação omissiva atribuída ao poder público e o dano causado a terceiro. III. Latrocínio praticado por quadrilha da qual participava um apenado que fugira da prisão tempos antes: neste caso, não há falar em nexo de causalidade entre a fuga do apenado e o latrocínio. Precedentes do STF: RE 172.025/RJ, Ministro Ilmar Galvão, "D.J." de 19.12.96; RE 130.764/PR, Relator Ministro Moreira Alves, RTJ 143/270. IV. - Reconhecido e provido. (RECURSO EXTRAORDINÁRIO 369820, 2003).

Os Tribunais brasileiros observam o ato administrativo no caso de omissão, deve ser causa direta e imediata, não podendo impedir o evento, citando-se como exemplo, os casos de acidente de aluno em colégio público (durante a aula), bem como morte de detendo em penitenciária.

$\mathrm{O}$ ato omissivo do Estado deve ser a causa do dano, e nessa linhagem que o §6. ㅇ do artigo 37 da Constituição Federal, inclui além da responsabilidade pelos atos comissivos, também os omissivos. Conforme mostra jurisprudência:

Responsabilidade civil do Estado. Ato omissivo. Detento morto por companheiro de cela. A teoria hoje dominante é a que baseia a responsabilidade do Estado, objetivamente, no mau funcionamento do serviço, independentemente da culpa do agente administrativo. Culpa provada dos agentes da Administração por omissão concorrente para a construção do evento danoso. Recurso extraordinário do Estado não conhecido (RECURSO EXTRAORDINÁRIO 84072, 1976).

Portanto, quando algum detento que esteja sob a Tutela do Estado venha a falecer, os tribunais têm aplicado a responsabilidade objetiva no que se refere ao nexo de causalidade nas condutas omissivas artigo $5 .^{\circ} \mathrm{XLIX}$ da Constituição Federal de 1988 - na medida em que Estado é obrigado a zelar pela integridade moral e física dos presos.

Cahali (2007, p.317-318), cita a seguinte jurisprudência:

TJSP, 8. a Câmara, 24.10.1984, RJTJSP 93/156. STF, 1.ㄹ TURMA: Indenização - Dano causado a aluno por outro aluno igualmente matriculado na rede pública de ensino - Perda do globo ocular direito decidido por maior - Fato ocorrido no recinto da escola pública municipal Configuração da responsabilidade objetiva do Município. A obrigação governamental de preservar a intangibilidade física dos alunos, enquanto estes se encontram no recinto de estabelecimento escolar, constitui encargos indissociável do dever que incumbe ao Estado de dispensar proteção efetiva a todos os estudantes sob a guarda imediata do Poder Público nos estabelecimentos oficias de ensino (rel. Celso de Mello, 28.05.1996, RT 733/130). No mesmo sentido TJPR, 1. a Câmara, AC 33.518-8, 17.10.1995, Rep. IOB Jurispr. 1-9374; TJSP, 9.ㄹ Câmara, 26.11.1997, JTJ 203/102; 5. a Câmara, 23.03.2000, JTJ 230/83; 4. a Câmara, AC 83.289-5, 19.10.2000.

Impende colacionar, ainda, trecho de uma das jurisprudências mais citadas pelos doutrinadores, considerando-se um dos mais debatidos quando se trata do estudo da responsabilidade do Estado no que se refere às condutas omissivas, na aplicabilidade da teoria objetiva. $\mathrm{O}$ caso em tela, versa sobre uma aluna que se sofreu grave lesão ocular, ocasionada por uma agulha de injeção de posse de outro colega:

De outro lado, ainda que ausente qualquer responsabilidade da servidora municipal (professora de escola pública) na eclosão do evento que resultou a cegueira parcial da aluna de sua própria classe, e tal circunstância, por si só, não teria o condão de exonerar o município do Rio de Janeiro/RJ da responsabilidade civil - que é objetiva - decorrente do fato danoso em questão (RECURSO EXTRAORDINÁRIO 109.615, 1996).

Portanto, nos estabelecimentos escolares, a entidade pública é responsável por qualquer ato ocorrido ao estudante, portanto, necessário a maior diligência possível para evitar eventuais consequências levas que possam resultar perigo.

Nesse diapasão, o legislador constituinte também separou a responsabilidade, no entender de Meirelles (2006, p.658) como sendo aquela em "que o Estado indeniza a vítima; o agente indeniza o Estado, regressivamente."

O dever de indenizar, portanto, verifica uma consequência delimitada ao alvedrio da ação ou omissão geradora do dano, pressupondo que a responsabilidade civil existe na medida do prejuízo, que deverá ser ressarcido pelo lesante. Da mesma forma, existe, a contrapartida de que o causador direto do dano o 
recomponha, restaurando o equilíbrio subvertido ao Estado (Stoco, 2001, p.923).

O Estado será responsável, quando subsistir a comprovação de existência da ofensa e a relação de causa, gerando um resultado em relação à parte interessada. Apesar de entendimentos divergentes, podese concluir que a atual jurisprudência majoritária entende ser subjetiva a responsabilidade do Estado por omissão.

Assim, a responsabilidade é subjetiva, quando exigida a culpa ou o dolo no ato omissivo do poder público, quando derivado de negligência, imprudência ou imperícia. Ao arrimo da constituição, em seu artigo 37, § 6으, a regra adotada é a da responsabilidade objetiva, entretanto, grande se demonstra o número de casos em que a aplicabilidade é a da responsabilidade subjetiva, quando resultante da falta de serviço, ou, ainda, por culpa do serviço. Uma teoria é adotada pelo texto constitucional, mas conforme demonstrado, coexistente a convocação de duas teorias.

\section{CONSIDERAÇÕES FINAIS}

Analisando a responsabilidade civil do Estado por omissão, procedeu-se, inicialmente, com análise da teoria geral da responsabilidade civil, diferenciando, ainda, a responsabilidade subjetiva da objetiva, demonstrando os pressupostos necessários para caracterização e configuração do dever de indenizar.

Passou-se para as diferentes acepções entre ação e omissão no atuar do Estado. Analisando-se, ainda, os casos em que a conduta do Estado é omissiva, sendo que a tese que prevalece é a da responsabilidade subjetiva, embora alguns autores defendam a aplicação na forma objetiva.

O STF tem decidido no sentido de que somente no descumprimento do dever legal de agir, haverá responsabilização pela conduta omissiva, devendo haver comprovação da culpa.

Ainda que exista nexo de corrente plausível para aplicação da teoria objetiva na responsabilidade do Estado por omissão, impossível de ser aplicada, na medida em que o Estado brasileiro não tem suporte ou condições para responder por tudo aquilo que acontece na sociedade, desencadeando o dever de indenizar somente quando provar o rompimento do nexo de causalidade.

É em razão disso que a Suprema Corte se posiciona de forma a aplicar a teoria subjetiva. Levando em consideração que o STF é um órgão político, dificilmente teria posicionamento que comprometesse tanto as finanças do Estado. A exigência da culpa, destarte, é um filtro criado para que o Estado não arque com prejuízos que não proporcionou diretamente.

\section{REFERÊNCIAS}

1. BANDEIRA DE MELLO, Celso Antônio. Curso de Direito Administrativo. 23aㅡ ed. São Paulo: Malheiros Editores, 2007.

2. CAHALI YS. Responsabilidade Civil do Estado. $3^{\underline{a}}$ ed. São Paulo: Malheiros, 2007.

3. CARVALHO FILHO JS. Manual de Direito Administrativo. 13aㅡ ed. Rio de Janeiro: Lúmen Júris, 2005.

4. CAVALIERI FILHO, Sergio. Programa de Responsabilidade Civil. $7^{7}$ ed. São Paulo: Atlas, 2007.

5. $\quad$ DI PIETRO, Maria Sylvia Zanella. Direito Administrativo. 14를 ed. São Paulo: Atlas, 2002.

6. MEIRELLES HL. Direito Administrativo Brasileiro. 18 ed. São Paulo: Malheiros, 1993.

7. MEIRELLES HL. Direito Administrativo Brasileiro. 32ª ed. São Paulo: Malheiros, 2006.

8. PEREIRA CMS. Instituições de Direito Civil. Volume I. Rio de Janeiro: Forense, 2004.

9. RECURSO EXTRAORDINÁRIO 84072. 1976. In: SUPREMO Tribunal Federal. Bahia: Relator Ministro Cunha Peixoto. Disponível em:http://stf.jus.br/portal/jurisprudencia/listarJurisprudencia.asp?s1=\%28RE+84072\%29\&base=baseAcordaos\&url=http://tinyurl.c om/ya64jinsy. Acesso em: 5 nov.2018.

10. RECURSO EXTRAORDINÁRIO 109615. 1996. In: ESTUDO de Administrativo. Rio de Janeiro: Relator Ministro Celso de Melo. Disponível em: http://estudodeadministrativo.com.br/informativo-035.php. Acesso em: 5 nov.2018.

11. RECURSO EXTRAORDINÁRIO 369820. 2003. In: SUPREMO Tribunal Federal. Rio Grande do Sul: Relator Ministro Carlos Velloso. Disponível em: http://stf.jus.br/portal/jurisprudencia/listarJurisprudencia.asp?s1=\%28RE+172025\%22\&base=ba se acordaos\&url=http://tinyurl.com/y9e6se9b. Acesso em: 5 nov.2018.

12. STOCO R. Tratado de Responsabilidade Civil. 5를 editora Revista dos Tribunais, 2001. 